\title{
Implementation of thermography for determination of air jet geometry in HVAC systems
}

\author{
by S. Švaićc, I. Boras* and D. Dović* \\ *Faculty of Mechanical Engineering and Naval Architecture, University of Zagreb, Croatia, ssvaic@fsb.hr
}

\begin{abstract}
A properly designed room air diffusion scheme ensures that when conditioned air is supplied into a room, it causes no discomfort to the occupants. To confirm the design characteristic of an air diffusion arrangement, a measurement of different parameters of air movement pattern like jet geometry, air temperature and velocity or humidity must be done. IR thermography can be successfully applied for quick determination of the air jet geometry, not only for new and existing systems, but also in the design phase of air inlets and outlets. The paper presents the possibilities for determination the jet geometry by means of IR thermography. The results presented are obtained on three outlet geometry (circular, square and rectangular).
\end{abstract}

Key words: HVAC systems, air movement patterns, IR thermography

\section{Introduction}

With conventional diffusion arrangements, primary air is supplied over the occupied zone where it entrains and mixes with room secondary air. This process results in decay of the initial temperature and velocity difference between the supply and room air, so that when the supply jet reaches the occupied zone the velocity and temperature are close to room conditions. To obtain the designed parameters, air outlets and inlets must be properly selected and balanced and the predicted air movement patterns achieved. For evaluation of the air movement patterns, IR thermography can be applied as a method for quick determination of air jet geometry. The method was investigated in the Laboratory for Applied Thermodynamic, Faculty for Mechanical Engineering and Naval Architecture, University of Zagreb, and the results are presented in this paper.

\section{Air jet, terms and definitions}

It is important to understand some of the basic terms when air jets are the primary factor affecting room air motion.

If the air jet is not obstructed by walls or other obstructions it is called free jet.

There are jets whose air motion is attached to the surface when then they are called attached air jets.

Based on placement and flow characteristics jet can be confined jet. This is case when air jet movement pattern is influenced by reverse flow created by the same jet.

If the temperature of the supplied air is equal to the ambient air temperature, the jet is called isothermal jet. When there is a temperature difference between supplied and ambient air, the jet is called non-isothermal jet.

Another classification depending on air jet diffuser type can be found in [1]

Air jet geometry:

Basic terms concerning air jet geometry.

Throw or radius of diffusion is the forward travel of a jet to the point where the maximum velocity has decayed to a nominated terminal velocity.

Drop or rise is the distance between the jet centerline and supply outlet centerline at nominated throw.

Entrainment or induction is the movement of room air into the jet caused by the air stream discharged from the outlet secondary air motion

Envelope is a jet area within the boundary of a nominated air velocity.

Expansion or spread is normal divergence of a jet as it leaves an outlet and entrains surrounding air. 

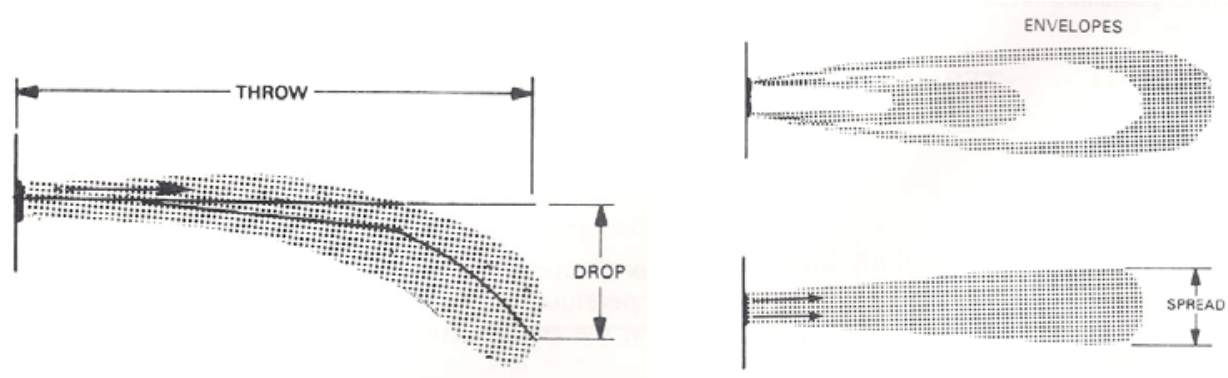

Fig. 1. Air jet throw, drop, envelopes and spread

Drop is a vertical distance that the lower edge of a horizontally projected stream drops between the outlet and the end of its throw.

Outlet velocity is the average velocity of air emerging from the outlet, measured in the plane of the opening.

Terminal velocity is the maximum air stream velocity at the end of the throw

\section{Air jet theory and characteristic}

In the subsequent text are described basic terms concerning air jet theory of both, isothermal and non-isothermal jets, [1].

\subsection{Isothermal circular free jet}

For many conditions of jet discharge, it is possible to analyze jet performance which means to determine:

1. Angle of divergence

2. Velocity patterns along the jet axis

3. The velocity profile at any cross section in the zone of maximum engineering importance

4. The entrainment ratios in the same zone

\section{- Angle of divergence}

Measured angle of divergence for discharge into large open spaces usually range from 20 to $24^{\circ}$ with an average of $22^{\circ}$. Coalescing jets for closely spaced multiple outlet expand at smaller angles, averaging $18^{\circ}$, and jets discharging into relatively small spaces show even smaller angles of expansion. In cases where the outlet area is small compared to the dimensions of the space normal to the jet, the jet may be considered free as long as

$$
X \leq 1.5 \sqrt{A}
$$

where $X$ is a distance from the face outlet and $A$ cross-sectional area of confined space normal to the jet.

\section{- Jet expansion zones}

Standard terms which define the yet

$v_{x}=$ centerline velocity at distance $x$ from the outlet, $(\mathrm{m} / \mathrm{s})$

$v_{0}=v_{\mathrm{c}} / C_{\mathrm{d}} R_{\mathrm{fa}}=$ average initial velocity at discharge, $(\mathrm{m} / \mathrm{s})$

$C_{d}=$ discharge coefficient (usually between 0.65 and 0.9 )

$R_{f a}=$ ratio of free are to core area

$x=$ distance from outlet to measurement of centerline velocity, $(\mathrm{m})$

$y=$ distance from the centerline at $x(\mathrm{~m})$

$Y=$ drop or rise of an air jet at $x(\mathrm{~m})$

$H_{0}=$ width of jet at outlet or at vena contracta, $(\mathrm{m})$

$D_{0}=$ effective or equivalent diameter of stream at discharge

$A_{0}=A_{\mathrm{c}} C_{\mathrm{d}} R_{\mathrm{fa}}=$ effective area of stream at discharge

$K, K^{\prime}=$ constants

The full length of an air jet, in terms of maximum velocity and temperature differential at the cross section, can be divided into four zones. 
$1^{\text {st }}$ ZONE - A core zone; a short zone, extending about four diameters or widths from the outlet face, in which the ratio $\frac{v_{x}}{v_{0}}$ remains constant and equal to the ratio of the center velocity of the jet at the start of expansion to the average velocity. The ratio varies from approximately 1.0 for rounded entrance nozzles to about 1.2 for straight pipe discharges. It has much higher values for diverging discharge outlets.

$2^{\text {nd }}$ ZONE - A transition zone where the jet velocity varies inversely with square root of throw. The zone length depends on the type of outlet, initial airflow turbulence and so forth, but is approximately equal to 8 hydraulic diameters.

$$
\frac{v_{x}}{v_{0}}=\sqrt{\frac{K^{\prime} H_{0}}{x}}
$$

Table 1. Values for $K^{\prime}$ for various standard openings [1]

\begin{tabular}{|c|c|c|c|c|}
\hline \multirow[b]{2}{*}{ Type of Outlet } & \multicolumn{2}{|c|}{$\boldsymbol{K}$} & \multicolumn{2}{|c|}{$\boldsymbol{K}^{\prime}$} \\
\hline & $\begin{array}{c}V_{o}= \\
2.5 \text { to } \\
5.0 \mathrm{~m} / \mathrm{s}\end{array}$ & $\begin{array}{c}V_{o}= \\
10 \text { to } \\
50 \mathrm{~m} / \mathrm{s}\end{array}$ & $\begin{array}{c}V_{o}= \\
2.5 \text { to } \\
5.0 \mathrm{~m} / \mathrm{s}\end{array}$ & $\begin{array}{c}V_{o}= \\
10 \text { to } \\
50 \mathrm{~m} / \mathrm{s}\end{array}$ \\
\hline \multicolumn{5}{|l|}{ Free openings } \\
\hline Round or square & 5.0 & 6.2 & 5.7 & 7.0 \\
\hline $\begin{array}{l}\text { Rectangular, large } \\
\text { aspect ratio }(<40)\end{array}$ & 4.3 & 5.3 & 4.9 & 6.0 \\
\hline $\begin{array}{l}\text { Annular slots, axial } \\
\text { or radial }^{\mathrm{a}}\end{array}$ & - & - & 3.9 & 4.8 \\
\hline \multicolumn{5}{|l|}{ Grilles and grids } \\
\hline Free area $40 \%$ or more & 4.1 & 5.0 & 4.7 & 5.7 \\
\hline \multicolumn{5}{|l|}{ Perforated panels } \\
\hline Free area 3 to $5 \%$ & 2.7 & 3.3 & 3.0 & 3.7 \\
\hline Free area 10 to $20 \%$ & 3.5 & 4.3 & 4.0 & 4.9 \\
\hline
\end{tabular}

$3^{\text {rd }}$ ZONE - A zone of fully established turbulent flow that may be long from 25 to 100 equivalent outlet diameters. This zone is of major engineering importance because, in most cases, the diffuser jet enters the occupied area within this zone. Centerline velocities can be determined from: [2]

$$
\frac{v_{x}}{v_{0}}=\frac{1}{m} \frac{D_{0}}{x}
$$

Constant $m$ is called mixing factor and its value depends on level of outlet air turbulence and on outlet type. Usual values of factor $\mathrm{m}$ lie between 0.1 and 0.5 .

Ratio $x_{0}=\frac{D_{0}}{m}$ is called fictional jet core length and jet has longer core if level of turbulence is smaller.

Velocity profile at any cross section can be calculated from:

$$
\frac{V_{y}}{v_{x}}=e^{-2\left(\frac{y}{m x}\right)^{2}}=e^{-0.69\left(\frac{y}{y a}\right)^{2}}
$$

where ya represents distance where $v_{\mathrm{x}}=0.5 v_{\mathrm{y}}$

It can be seen that all profiles at $x>x_{0}$ are similar and can be showed in the same diagram, shown on figure 2 . 


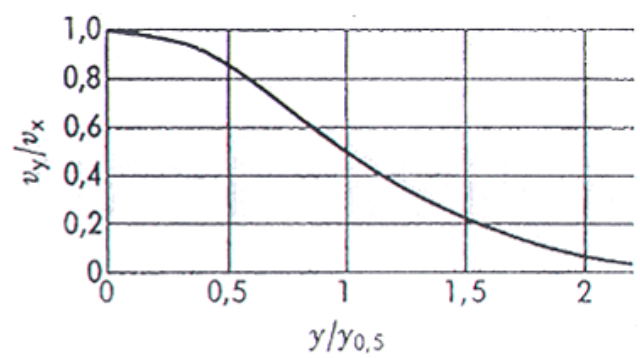

Fig. 2. Dimensionless profile for circular free jet

$4^{\text {th }}$ ZONE - A zone of diffuser jet degradation where the maximum air velocity and temperature decreases rapidly. The distance to this zone and its length depend on the velocities and turbulence characteristics of ambient air. After just a few diameters or widths, the air velocity drops to the nominated terminal velocity, usually $0.25 \mathrm{~m} / \mathrm{s}$.

In this zone centerline velocity is inversely proportional with squared distance $x$.

$$
\frac{v_{x}}{v_{0}} \propto \frac{1}{x^{2}}
$$

\subsection{Non-isothermal circular free jet}

When the temperature of introduced air is different from the room temperature, a movement pattern of diffuser air jet is affected by the thermal buoyancy due to air density difference. Behaviour of the air jet will depend on magnitude of gravitational and inertial force. There are two distinct cases which can occur; [2]

- Gravitational and inertial forces have the same direction. That happened when warm air is introduced from the floor or cold air from the ceiling.

- These two forces may have opposite direction, when warm air is introduced from the ceiling or cold from the floor. Direction of the air jet in this case will depend on magnitudes of these forces and may become opposite from the introducing direction.

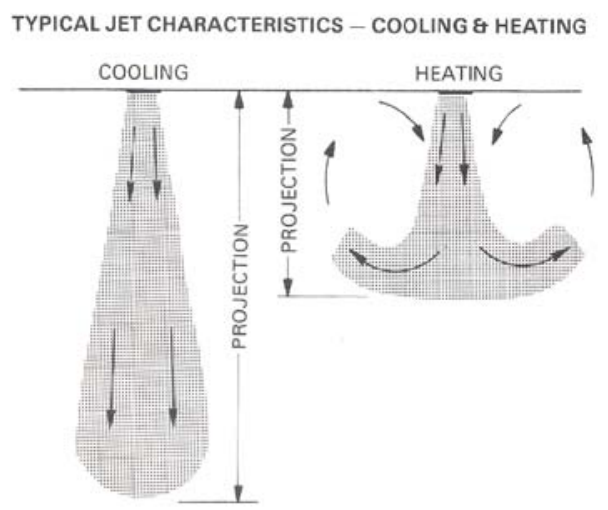

Fig. 3. Non-isothermal vertical jet

Ratio of these two mentioned force is called Archimedes number;

Gravitational force depends on temperature difference of introduced and room air. On the other hand, inertial force is proportional to the squared outlet velocity. Now, for the circular free jet, Archimedes number is defined as follows:

$$
\operatorname{Ar}=\frac{g \cdot \Delta T_{0} \cdot D_{0}}{T_{0} \cdot v_{0}^{2}}
$$


where

$\Delta T_{0}$ - temperature difference of ambient and supply air

$T_{0}$ - room air temperature

Corresponding formula for calculating drop or rise of an air jet at distance $x$ from outlet is:

$$
\frac{Y}{D_{0}}= \pm 0.06 \cdot \operatorname{Ar} \cdot\left(\frac{x}{D_{0}}\right)^{3}
$$

It is important to emphasize that throw of non-isothermal horizontal jet doesn't differ much from the throw of isothermal jet.

\section{Application of IR thermography for determination of air jet geometry}

The method developed at the Laboratory for Applied Thermodynamic tends to visualize the temperature distribution in non-isothermal air jets. A curtain made of a material having a low heat conduction coefficient (paper, textile etc.) is inserted perpendicular to the jet outlet, along its centerline and positioned vertically. The hot or cold air stream passing along the curtain leaves on its surface a temperature track having the shape of jet geometry. This temperature field is recorded in stationary state using the IR thermographic camera.
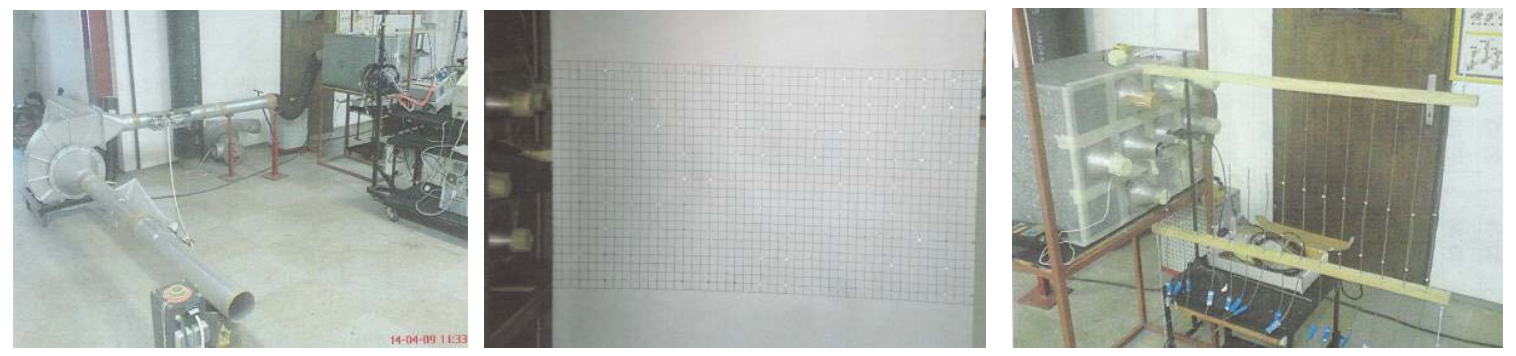

Fig. 4. Experimental rig

Figure 5 shows the recorded thermogram of air jet. Hot air exits from the circular opening with the temperature of $30{ }^{\circ} \mathrm{C}$, and velocity of $0.9 \mathrm{~m} / \mathrm{s}$ and passes along the curtain.

The experiment consisted of two separate measurements. First, the air jet stream has been recorded with the IR thermographic camera and compared with the results measured by means of thermocouples along the centerline. Beside temperatures, the velocities along the centerline were also measured. Results are shown on figure 5. 

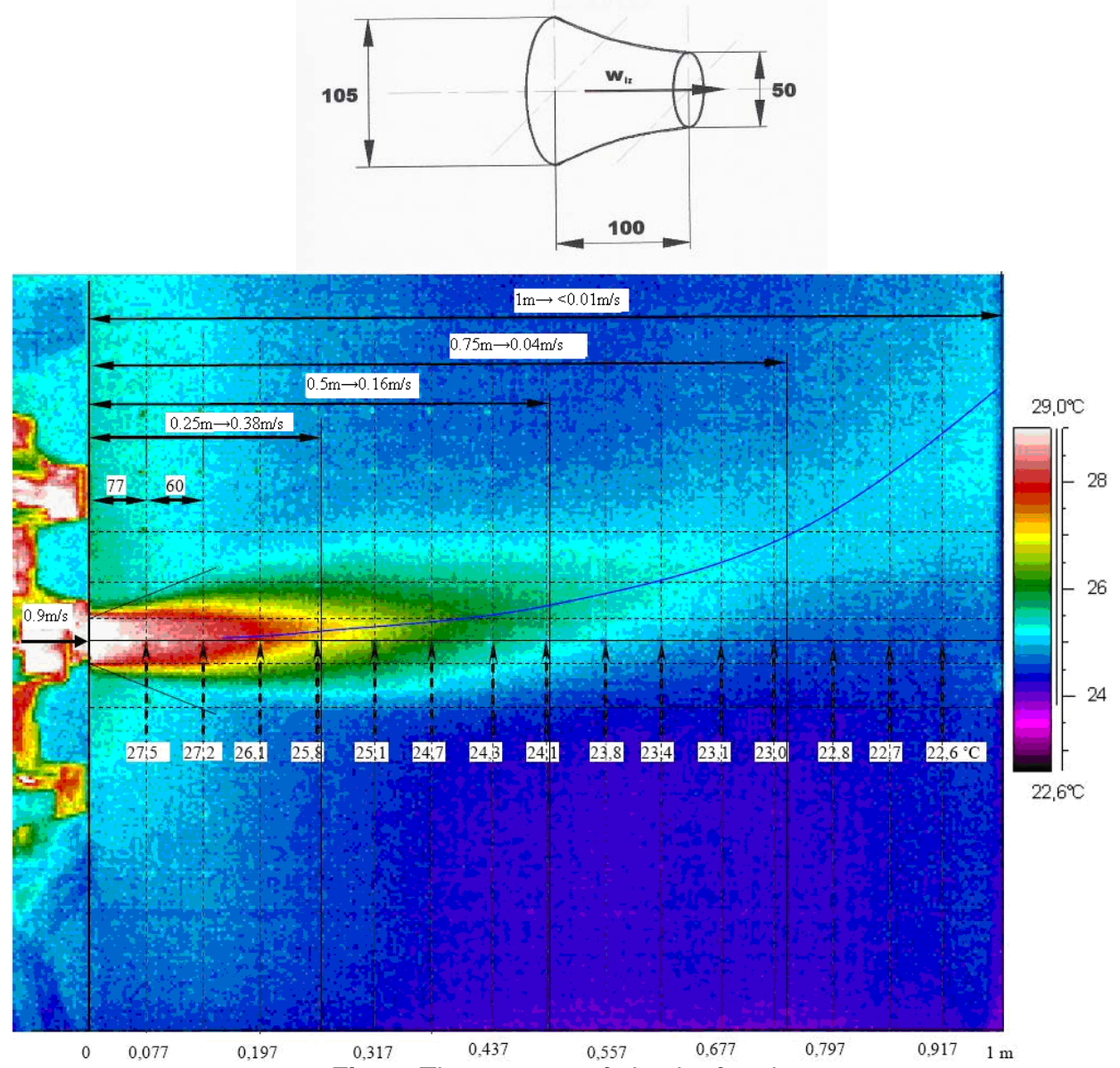

Fig. 5. Thermogram of circular free jet

Outgoing velocity $0.9 \mathrm{~m} / \mathrm{s}$ and theoretical spread angle $24^{\circ}$ are marked on the left side of the thermogram. Figure 6 shows the temperatures profiles obtained by thermocouples and IR camera.

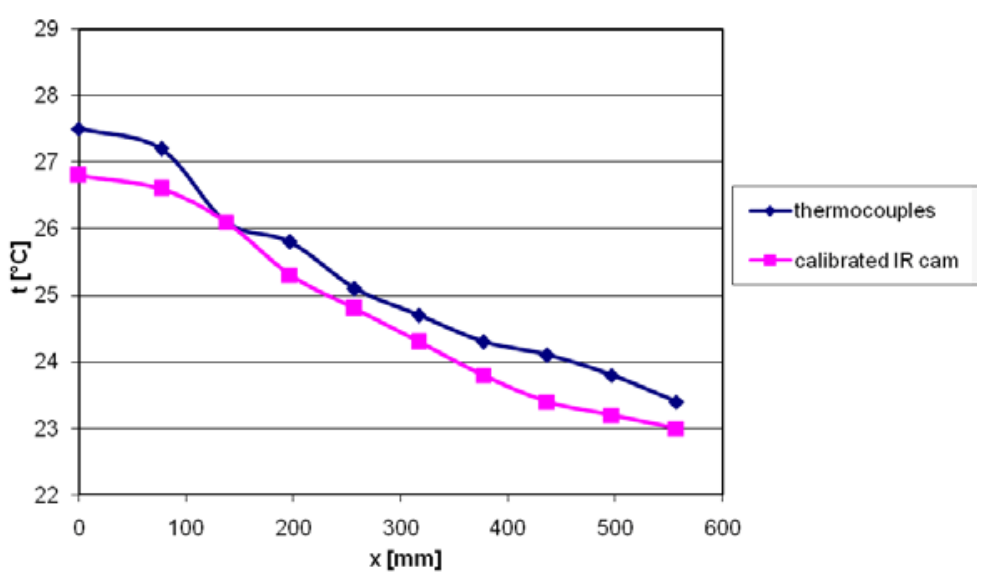

Fig. 6. Temperature profile along air jet centreline (circular outlet)

In order to calculate theoretical velocity profile, according to Eq. (3), it is necessary to find the mixing factor $m$. From the figure 5 the jet core length is estimated $100 \mathrm{~mm}$ what gives the mixing factor of: 


$$
m=\frac{d}{x_{0}}=\frac{0.05}{0.1}=0.5
$$

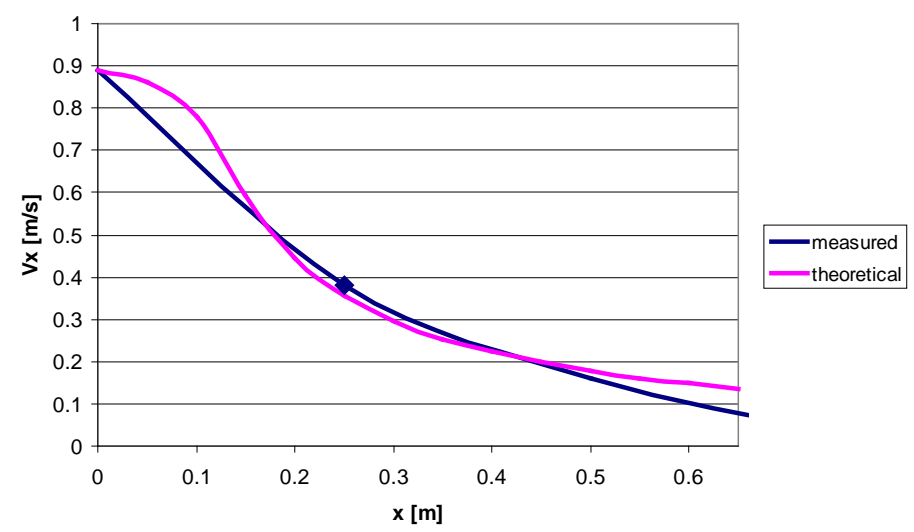

Fig. 7. Comparison of measured and calculated velocity profiles (circular outlet)

The experiment was repeated with the square and rectangular outlets too. The thermograms obtained are shown on figures. 8 and 9.

Flow parameters and outlet geometry are provided in table 2.

Table 2. Test conditions and outlet geometry

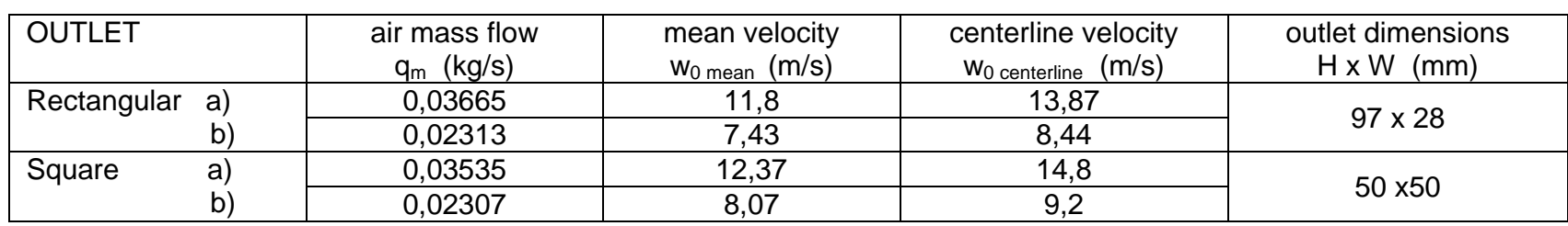

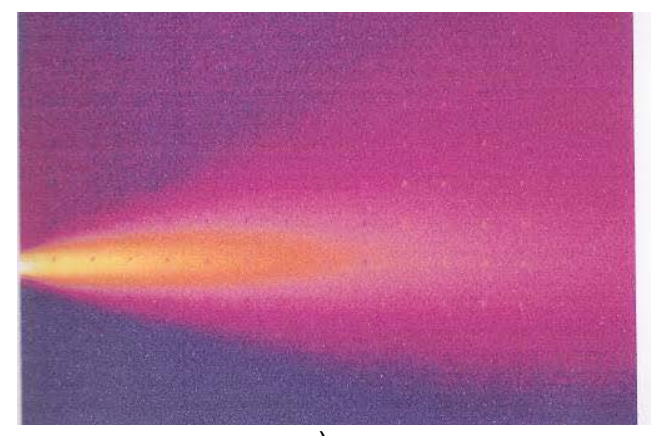

a)

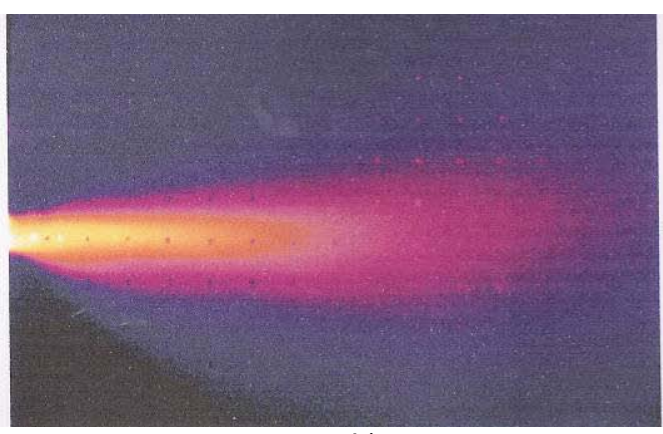

b)

Fig. 8. Square outlet, air jet thermograms obtained for two different mass flows (see Table 2) 


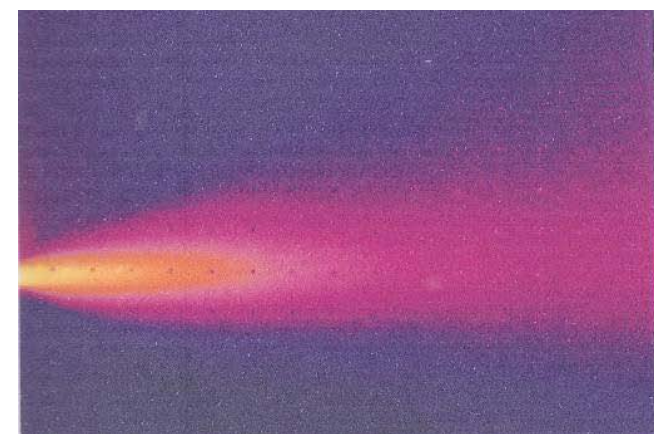

a)

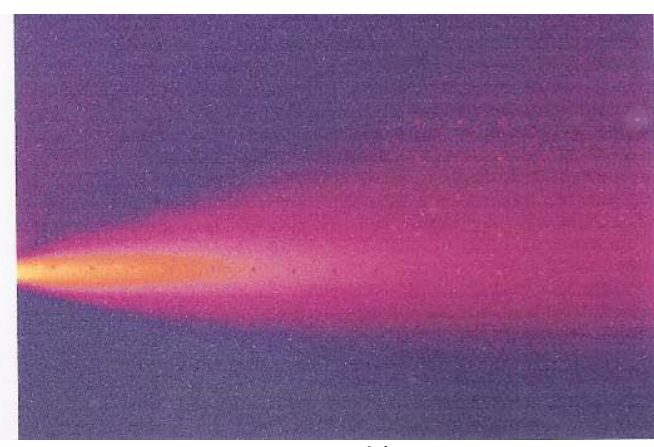

b)

Fig. 9. Rectangular outlet, air jet thermograms obtained for two different mass flows (see Table 2)

Temperatures obtained from the thermograms and by thermocouples were similar to each other as well as are the measured and calculated velocities. The same applies to the experiment with circular opening.
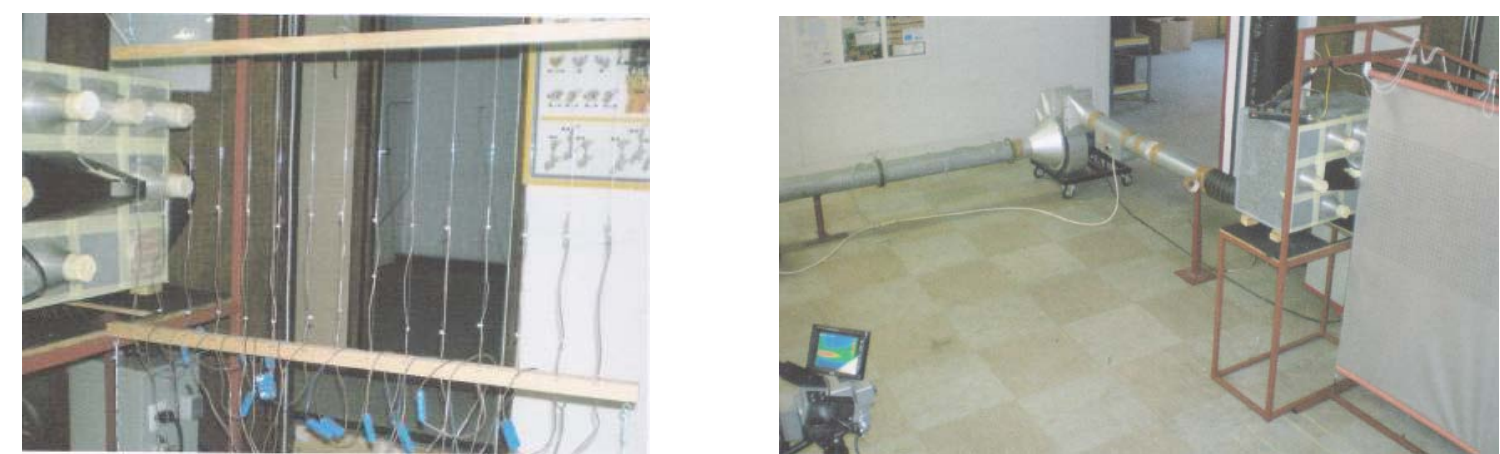

Fig. 10. Temperature measurements (thermocouples and thermography)

Temperatures obtained from the thermograms and by thermocouples correspond very good to the theoretically obtained ones, as well as match well the measured to calculated velocities. The same can be concluded from the results of experiment with circular opening. The results for square outlet (thermogram, figure 8 a) are given in figures 11 and 12 .

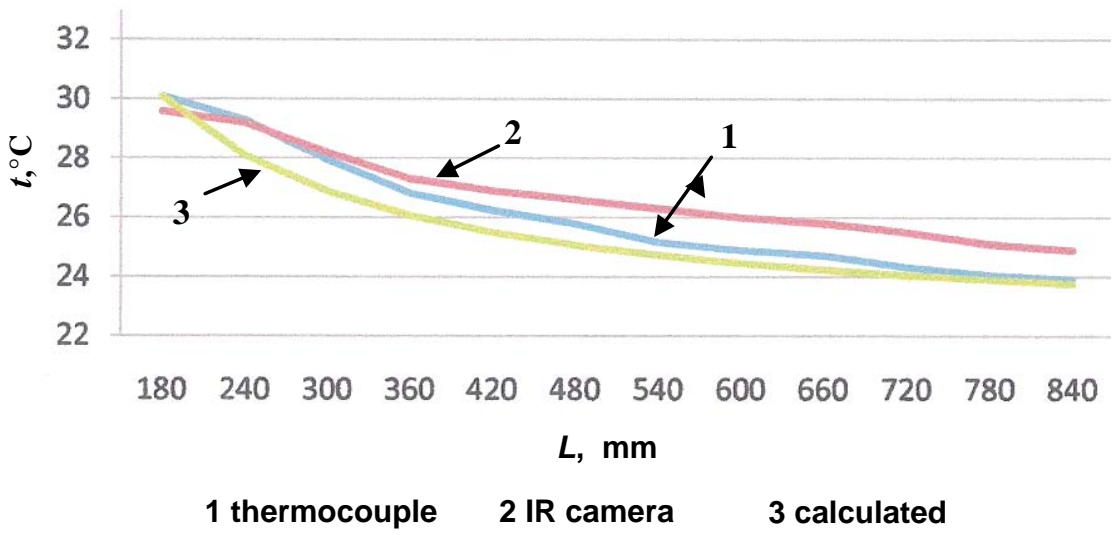

Fig. 11. Temperature distributions along the centreline corresponding to figure 8 a) (square outlet) 


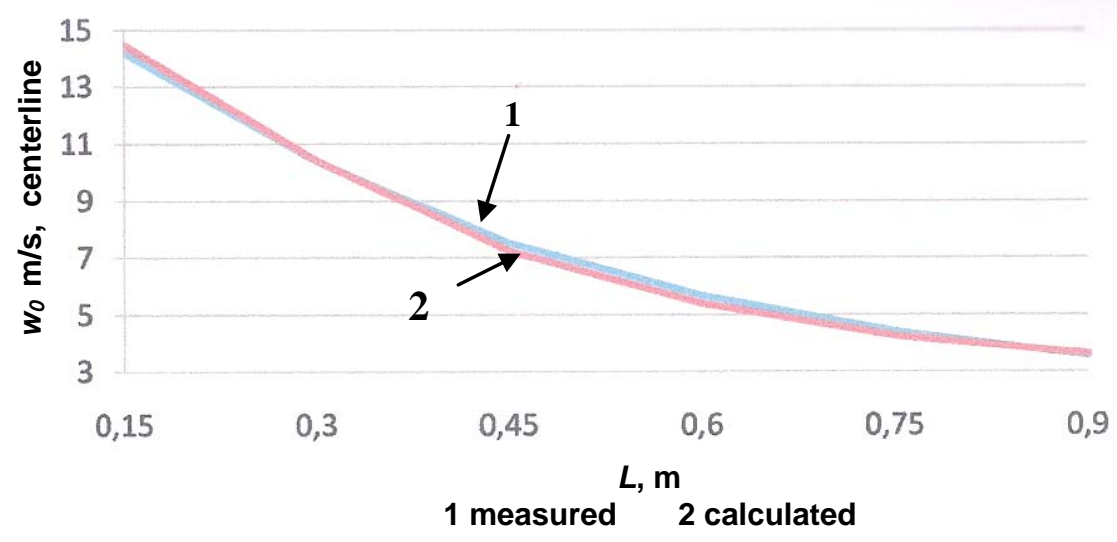

Fig. 12. Velocity distributions along the centerline corresponding to figure 8 a) (square outlet)

\section{Conclusion}

According to the results presented, it can be concluded that the presented method which includes IR thermography can be successfully applied for determination of the air jet geometry in HVAC systems. The method is based on relatively easy and cheap measurements whose results can provide better insight and prediction of air movement patterns and thermal phenomenon in HVAC systems. Further research will be directed to quantify the parameters such as induction and flow patterns for different types of air outlets.

\section{REFERENCES}

[1] ASHRAE Handbook - Fundamentals, ASHRAE Atlanta, 1997.

[2] ASHRAE Handbook - Fundamentals, ASHRAE Atlanta, 2005.

[3] Recknagel, Sprenger, Schramek: "Taschenbuch für Heiyung + Klimatechnik", Oldenbourg Industrieverlag GmbH, München, 2004.

[4] Andrassy M., Boras I. and Svaic S.: "Basics of thermography and applications", Kigen d.o.o., Zagreb, 2008.

[5] Gioodfelow H., Tahti E.: "Industrial Ventilation Design Guidebook", Academic Press, San Diego, California, 2001.

[6] Awbi H.B.: "Ventilation of Buildings", Spon Press, Taylor\&Francise Library, 2005. 